\title{
Microalbuminuria predicts the development of serum lipoprotein abnormalities favouring atherogenesis in newly diagnosed Type 2 (non-insulin-dependent) diabetic patients
}

\author{
L. Niskanen ${ }^{1}$, M. Uusitupa ${ }^{2}$, H. Sarlund ${ }^{1}$, O. Siitonen ${ }^{1}$, E. Voutilainen ${ }^{1}$, I. Penttilä ${ }^{3}$ and K. Pyörälä ${ }^{1}$ \\ Departments of ${ }^{1}$ Medicine, ${ }^{2}$ Clinical Nutrition and ${ }^{3}$ Clinical Chemistry, Kuopio University Central Hospital, Kuopio, Finland
}

\begin{abstract}
Summary. We studied the relationship of slight albuminuria (microalbuminuria) to serum lipid and lipoproteins in a representative group of middle-aged Type 2 (non-insulin-dependent) diabetic patients. A random sample of non-diabetic control subjects was also examined. Diabetic patients had both at diagnosis and after five years higher total, LDL- and VLDL-triglyceride levels and higher VLDL-cholesterol, but lower HDL-cholesterol levels than non-diabetic subjects. No consistent difference was found in LDL-cholesterol levels between diabetic and non-diabetic subjects. The prevalence of microalbuminuria ( $>35 \mathrm{mg} / 24 \mathrm{~h}$ ) remained about the same in diabetic patients at both examinations (19-20\%). The diabetic patients with persistent microalbuminuria were slightly hyperglycaemic and they tended to have lower creatinine clearance at the 5-year examination than those without persistent microalbuminuria. There were no differences in the blood pressure levels or the occurrence of hypertension between the diabetic groups with and without microalbu-
\end{abstract}

minuria. At the baseline examination, no differences were seen in serum lipids and lipoproteins between diabetic patients with and without microalbuminuria. In patients with persistent microalbuminuria, a statistically significant increase in VLDL-cholesterol $(p<0.05)$ and VLDL- and LDLtriglyceride levels $(p<0.05)$ and a decrease in HDL-cholesterol level $(p<0.05)$ was seen at the 5-year follow-up. These changes could not be explained by age, sex, body mass index or $\mathrm{HbA}_{1}$. In conclusion, persistent microalbuminuria predicts and aggravates abnormalities in lipoprotein composition and a decrease in HDL-cholesterol in patients with Type 2 diabetes mellitus. The excess cardiovascular morbidity and mortality in diabetic patients with increased albuminuria may, in part, be explained by these lipoprotein $a b-$ normalities.

Key words: Microalbuminuria, serum lipids, lipoproteins, Type 2 (non-insulin-dependent) diabetes.
Slightly increased albumin excretion in the urine, (microalbuminuria) predicts the development of a more marked proteinuria and clinical nephropathy in patients with Type 1 (insulin-dependent) [1] as well as in patients with Type 2 (non-insulin-dependent) diabetes mellitus [2]. Furthermore, it has been shown that albuminuria is associated with increased cardiovascular mortality in both Type 1 [3] and Type 2 diabetes [2, 4-6], as well as in non-diabetic subjects [7]. Among subjects with Type 2 diabetes, manifest renal failure is uncommon accounting for about only $3-5 \%$ of total mortality $[2,4,5]$ whereas increased cardiovascular mortality is the major cause of shortened lifespan of patients with Type 2 diabetes in most Caucasian populations [8]. Type 1 diabetic patients with albuminuria tend to have aggregation of risk factors for atherosclerotic vascular disease, e.g. increased prevalence of hypertension, elevated LDL-cholesterol, VLDL-cholesterol, and triglyceride levels and lowered HDL-cholesterol levels [3, 9-15]. It has been suggested that this adverse pattern of risk factors may favour the development of atherosclerotic complications in these patients [16]. In a cross-sectional study, Type 2 diabetic subjects with microalbuminuria showed also lower HDL-cholesterol and higher triglycerides than those without it [17], but on the whole the knowledge on the relationship between microalbuminuria and lipoprotein abnormalities in Type 2 diabetes is small. Due to the lack of prospective studies, it is unclear whether increased albuminuria represents an unspecific manifestation of generalised atherosclerosis or whether the presence of albuminuria itself possesses unfavourable effects on cardiovascular risk factors in Type 2 diabetes. We report the results of a prospective study concerning microalbuminuria and serum lipid and lipoprotein abnormalities in a representative group of middle-aged patients with newly diagnosed Type 2 diabetes and corresponding control subjects who were examined twice with a 5-year interval. 
Table 1. Clinical and biochemical characteristics of diabetic patients at the baseline and 5-year examinations according to persistent microalbuminuria $^{\text {a }}(A \mathrm{U} \geq 35 \mathrm{mg} / 24 \mathrm{~h}$ )

\begin{tabular}{|c|c|c|}
\hline Variable & $\begin{array}{l}\mathrm{AU}+ \\
(n=12)\end{array}$ & $\begin{array}{l}\mathrm{AU}- \\
(n=101)\end{array}$ \\
\hline \multicolumn{3}{|l|}{ Baseline examination } \\
\hline Male/female & $8 / 4$ & $51 / 50$ \\
\hline Age (years \pm SEM) & $55 \pm 2$ & $56 \pm 1$ \\
\hline Body mass index $\left(\mathrm{kg} / \mathrm{m}^{2}\right)$ & $30 \pm 2$ & $30 \pm 1$ \\
\hline Fasting blood glucose $(\mathrm{mmol} / \mathrm{l})$ & $9.5 \pm 0.8$ & $10.5 \pm 0.4$ \\
\hline Serum creatinine $(\mu \mathrm{mol} / \mathrm{l})$ & $81 \pm 6$ & $76 \pm 1$ \\
\hline Fasting plasm & $20 \pm 4$ & $24 \pm 2$ \\
\hline Systolic blood pressure $(\mathrm{mm} \mathrm{Hg})$ & $149 \pm 4$ & $149 \pm 2$ \\
\hline Diastolic blood pressure ( $\mathrm{mm} \mathrm{Hg}$ ) & $90 \pm 2$ & $93 \pm 1$ \\
\hline Hypertension $^{b}$ & $6(50 \%)$ & $69(68 \%)$ \\
\hline \multicolumn{3}{|l|}{ 5-year examination } \\
\hline Body mass index $\left(\mathrm{kg} / \mathrm{m}^{2}\right)$ & $29 \pm 2$ & $29 \pm 1$ \\
\hline $\mathrm{HbA}_{1}(\%)$ & $10.0 \pm 0.5$ & $9.1 \pm 0.2$ \\
\hline Fasting plasma glucose (mmol/l) & $12.8 \pm 0.1$ & $11.5 \pm 0.4$ \\
\hline Serum creatinine $(\mu \mathrm{mol} / \mathrm{l})$ & $92 \pm 6$ & $84 \pm 1$ \\
\hline Creatinine clearance $\left(\mathrm{ml} \cdot \mathrm{s}^{-1} \cdot \mathrm{m}^{2-1}\right)$ & $0.99 \pm 0.11$ & $1.18 \pm 0.04$ \\
\hline Plasma fibrinogen $(\mathrm{g} / \mathrm{l})$ & $3.5 \pm 0.5$ & $3.0 \pm 0.1$ \\
\hline Fasting plasma insulin (mU/1) & $31 \pm 10$ & $21 \pm 2$ \\
\hline Systolic blood pressure (mm Hg) & $139 \pm 5$ & $145 \pm 2$ \\
\hline Diastolic blood pressure ( $\mathrm{mm} \mathrm{Hg}$ ) & $83 \pm 2$ & $85 \pm 1$ \\
\hline Hypertension $^{\mathrm{b}}$ & $7(58 \%)$ & $58(57 \%)$ \\
\hline
\end{tabular}

a $\mathrm{AU}$ both at the baseline and at the 5 -year examination; ${ }^{b}$ Drug treatment and/or blood pressure $\geq 160 / 95 \mathrm{~mm} \mathrm{Hg}$

\section{Subjects and methods}

\section{Subjects}

The original study population consisted of 133 patients aged 45 to 64 years with newly diagnosed Type 2 diabetes and 144 randomly selected non-diabetic control subjects in the same age group. The collection of both groups was carried out during the period from 1 May 1979 to 31 December 1981. Both groups were recruited from a defined area of 180,000 inhabitants in the county of Kuopio in Eastern Finland. Approval for the study was given by the ethics committee of Kuopio University and the University Central Hospital. Informed consent was given by all subjects included in the study.

The diabetic patients ( 70 men, 63 women) were referred to the study by general practitioners working in community health centres in the survey area. The diagnosis of diabetes was primarily made in the clinical setting [18] and it was confirmed by an oral glucose tolerance test using diagnostic criteria recommended by the World Health Organisation's expert committee on diabetes mellitus [19]. Subjects whose fasting blood glucose had exceeded $7.0 \mathrm{mmol} / \mathrm{l}$ for more than six months as well as subjects with secondary diabetes, thyroid diseases, alcoholism, renal insufficiency, overt carcinoma or those in institutional care were not eligible for the study. All the diabetic patients were non-ketotic at the time of diagnosis and none needed insulin treatment during the follow-up period which was at least three months. The non-diabetic control population of the same age group ( 62 men, 82 women) was selected randomly from the population register. The formation of the study population, their representability and methods of the baseline examination have been described previously in detail [18]. The 5-year follow-up study of diabetic patients and non-diabetic control subjects was carried out between August, 1985 and January, 1986.

Eighty diabetic patients participated in a diet intervention study lasting for one year [20]. Other patients were referred to primary care after the baseline examination and the same applied also for the participants of the diet intervention study after its completion. During the follow-up eight diabetic patients (five men, three women) had died. Four diabetic (one man, three women) and five control subjects (one man, four women) refused to participate in the 5-year study. The data are given on those 113 diabetic patients $(59 \mathrm{men}$, 54 women) and 133 control subjects ( 57 men, 76 women) who participated both in the baseline and 5-year follow-up study and who also had full laboratory investigations, including the collection of $24 \mathrm{~h}$ urine specimen. The age of the subjects (mean \pm SEM) was $59 \pm 1$ years in diabetic men, $58 \pm 1$ years in control men $(p=$ NS) and $63 \pm 1$ years in diabetic women and $59 \pm 1$ years in control women $(p<0.05, t$-test $)$.

\section{Methods}

The examination of the 5-year follow-up study were carried out, whenever possible, according to the same methods and by the same personnel as in the baseline study. The methods and results concerning urinary protein excretion and renal function as well as the history and frequency of cardiovascular diseases at the baseline study have been published previously $[18,21]$.

Body mass index was calculated as body weight $(\mathrm{kg}) / \mathrm{height}\left(\mathrm{m}^{2}\right)$. Blood pressure was measured in the sitting position from the right arm after a $5 \mathrm{~min}$ rest with a mercury sphygmomanometer (cuff size $15 \times 42 \mathrm{~cm}$ ). Measurement was performed three times and the mean value of the three readings was used.

At the baseline examination, glucose determinations were conducted from whole blood by a glucose oxidase method (Glox KABI AB, Stockholm, Sweden). At the 5-year examination, glucose was determined by glucose dehydrogenase method (Merck Diagnostica, Darmstadt, FRG). Samples for plasma insulin and C-peptide determinations were collected in a fasting state before and at 1 and $2 \mathrm{~h}$ after an oral glucose load $(75 \mathrm{~g})$. Samples for plasma insulin were drawn into chilled tubes. After separation of plasma, samples were frozen immediately at $-70^{\circ} \mathrm{C}$ until analysis. At both examinations, plasma insulin was determined by RIA, but with different antiserum (M 8309, Novo, Copenhagen, Denmark, at the baseline examination; Phasedeph, Pharmacia Diagnostics, Uppsala, Sweden, at the 5-year examination). $\mathrm{HbA}_{I}$ was determined by column chromatography (Quick-step fast haemoglobin test system, Isolab, Akron, Ohio, USA) after incubation in $0.9 \% \mathrm{NaCl}$ solution for $12 \mathrm{~h}$. Serum lipids and lipoproteins were determined from fasting, fresh, unfrozen samples by a combined ultracentrifugation and precipitation technique [22]. The VLDL-fraction was separated by ultracentrifugation in the density of $1.006 \mathrm{~g} / \mathrm{ml}^{3}$. HDL was determined after magnesium chloride and dextran sulphate precipitation of the serum. $\mathrm{HDL}_{3}$ subfraction was separated running serum in the density of $1.125 \mathrm{~g} / \mathrm{ml}^{3}$ and the fractions were then separated by the tube slicing technique. The lipids of total serum and the fractions mentioned above were determined and the concentrations of the remaining lipoprotein fractions were calculated from these results. Commercial enzymatic methods were used in the determination of cholesterol (Monotest, Boehringer Mannheim, FRG) and triglycerides (Testcombination triglyceride, Boehringer Mannheim). Serum apoproteins $A_{1}\left(A p o A_{1}\right)$ and $B(A p o B)$ were determined from serum samples stored at $-70^{\circ} \mathrm{C}$. The analyses were performed by commercial immunochemical methods (Orion Diagnostica, Espoo, Finland). The $\mathrm{HDL}_{2}-$ and $\mathrm{HDL}_{3}$-cholesterol and $\mathrm{Apo} \mathrm{A}_{1}$ and Apo $\mathrm{B}$ levels were determined at the 5-year examination only, with the exception of Apo $A_{1}$ which was analysed in about two-thirds of diabetic and control subjects at the baseline examination [23].

At the 5-year study the morning urine sample was tested with a Nephur-Test-Leuco (Boehringer Mannheim, FRG) for the presence of nitrites, leucocytes, erytrocytes and protein. The abnormal urine samples were further studied by examining the urine sediment and bacterial culture. Those with evidence of infection were treated accordingly. For the collection of the $24 \mathrm{~h}$ timed urine sample, subjects were given individual oral and written instructions with plastic containers. The urine volume was measured and the urine aliquots were stored at $-70^{\circ} \mathrm{C}$ until analysis. At the baseline study the urinary albumin was measured by immunodiffusion (Behringwerke, 


\section{Baseline}

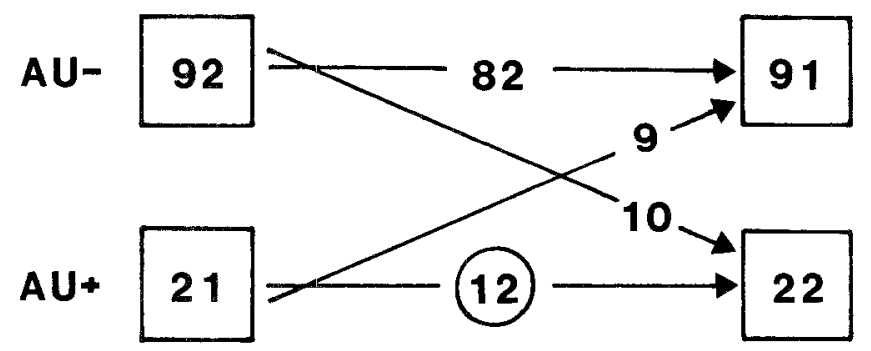

Fig. 1. Flow diagram of the occurrence of microalbuminuria $(\mathrm{AU} \geqslant 35 \mathrm{mg} / 24 \mathrm{~h})$ at the baseline and at the 5-year examination in diabetic subjects

Mahrburg Lahn, FRG) with a lower limit of assay of $0.8 \mathrm{mg}$ after concentration of the sample. Urinary albumin concentration was measured at the 5-year examination by turbidometry (Orion Diagnostica) by using IL Multistat III centrifugal analyser (IL Laboratories Inc., Lexington, Ky, USA). The lower limit of the assay was $8 \mathrm{mg}$. The presence of albuminuria was defined as a concentration exceeding the highest level of urinary albumin concentration ( $35 \mathrm{mg} / 24 \mathrm{~h}$ or $24 \mu \mathrm{g} / \mathrm{min}$ ) found in non-diabetic subjects with normal urinary sediment at the baseline examination. The serum and urine creatinine levels were determined with a multichannel analyser (Olli 3000, Kone Co., Espoo, Finland) by a modified Jaffe's method. The concentration of fibrinogen in plasma was measured at the 5-year examination by a modified thrombin time against a known amount of fibrinogen standard using reagents of Merz and Dade (Düdingen, Switzerland).

\section{Statistical analysis}

All values are given as mean \pm SEM or frequency tables. Differences between the groups were assessed by the analysis of covariance (ANCOVA), chi-square-test with Yate's correction or unpaired $t$ test. Time-related changes within the group were analysed by paired $t$-test. Pearson's correlation coefficient was calculated between the baseline albuminuria and albuminuria at the 5-year examination. Plasma insulin, total triglycerides and triglycerides in different lipoproteins were analysed after logarithmic transformation. All the analyses were carried out in the computing centre of the University of Kuopio by using the Statistical Package for Social Sciences (SPSS).

\section{Results}

On baseline examination both diabetic men (28.4 \pm $\left.0.5 \mathrm{~kg} / \mathrm{m}^{2}\right)$ and women $\left(28.7 \pm 0.7 \mathrm{~kg} / \mathrm{m}^{2}\right)$ showed a higher body mass index than non-diabetic men $\left(26.4 \pm 0.4 \mathrm{~kg} / \mathrm{m}^{2}\right.$, $p<0.01)$ and women $\left(27.7 \pm 0.6 \mathrm{~kg} / \mathrm{m}^{2}\right)$, although at the 5 -year examination the difference was not statistically significant in women.

Among all the diabetic patients participating in the 5-year examination, $36(56 \%)$ of the men and $23(40 \%)$ of the women were treated with diet only and $27(42 \%)$ of the men and $30(52 \%)$ of the women were on oral medication. Insulin treatment had been started in one man $(2 \%)$ and four women $(7 \%)$. On the average the metabolic control was rather poor both in diabetic men and women. The mean fasting plasma glucose and $\mathrm{HbA}_{1}$ levels were $11.5 \pm 0.5 \mathrm{mmol} / \mathrm{l}$ and $8.9 \pm 0.3 \%$ for men and $12.5 \pm 0.5 \mathrm{mmol} / \mathrm{l}$ and $9.6 \pm 0.3 \%$ for women.

At the baseline examination, 21 of $113(19 \%)$ of the diabetic patients showed microalbuminuria $(\geq 35 \mathrm{mg} /$ $24 \mathrm{~h}$ ) and the frequency of albuminuria at the 5-year examination was about the same (22 of $113,20 \%)$. The range of albuminuria at the 5-year examination was $<8 \mathrm{mg}-340 \mathrm{mg} / 24 \mathrm{~h}$. Figure 1 shows by flow diagram the occurrence of microalbuminuria in diabetic patients at the baseline and 5-year examination. Twelve diabetic patients had persistent elevation of urinary albumin excretion. At the baseline examination they had equal levels of microalbuminuria as compared to those nine diabetic patients with albuminuria at the baseline examination only. On the other hand, the baseline albumin excretion in the urine correlated to that of 5-year examination $(r=0.435$, $p<0.001)$. The clinical characteristics of diabetic patients with and without the persistent microalbuminuria are shown in Table 1 . There were no significant differences for age, sex distribution, body mass index, blood pressure, and prevalence of hypertension between these two groups. However, the $\mathrm{HbA}_{1}$ and fasting plasma insulin were slightly higher in diabetic patients with persistent microalbuminuria than in those without. Six of 12 diabetic subjects with persistent albuminuria were treated with diet only, five with oral hypoglycaemic agents and one with insulin. Serum creatinine was also somewhat higher and creatinine clearance lower in diabetic patients with persistent albuminuria. The atherosclerotic vascular disease (myocardial infarction or intermittent claudication) at baseline was found in 1 of $12(8 \%)$ diabetic patients with persistent albuminuria and in 24 of $101(24 \%)$ without albuminuria $(p=\mathrm{NS})$. The incidence of atherosclerotic vascular disease was $36 \%$ in diabetic patients with albuminuria and $27 \%$ in those without $(p=N S)$. There were no significant differences in the history of smoking and drug treatment for congestive heart failure between these two diabetic groups.

Table 2 shows the serum total cholesterol and lipoprotein cholesterol levels in diabetic subjects according

Table 2. Serum total cholesterol (Chol; mmol/l) and lipoprotein cholesterol levels in diabetic subjects in relation to microalbuminuria $(\mathrm{AU})$, and in control subjects at the baseline and at the 5-year examination

\begin{tabular}{ll}
\hline Chol LDL-Chol HDL-Chol VLDL-Chol \\
\hline Baseline
\end{tabular}

$\mathrm{AU}-(n=92) 6.36 \pm 0.13 \quad 4.16 \pm 0.11 \quad 1.07 \pm 0.03 \quad 1.23 \pm 0.08$

$\mathrm{AU}+(n=21) 6.66 \pm 0.30 \quad 4.19 \pm 0.22 \quad 1.07 \pm 0.06 \quad 1.41 \pm 0.24$

Control $(n=133) 6.75 \pm 0.11 \quad 4.57 \pm 0.10 \quad 1.38 \pm 0.03^{\mathrm{d}} 0.80 \pm 0.05$

5-year

AU - $\quad(n=91) 6.44 \pm 0.14 \quad 4.00 \pm 0.11 \quad 1.07 \pm 0.03 \quad 1.37 \pm 0.09$

$\mathrm{AU}+(n=22) 6.88 \pm 0.46 \quad 3.65 \pm 0.22 \quad 0.92 \pm 0.05^{\mathrm{a}} 2.32 \pm 0.42^{\mathrm{b}}$

Control $(n=126) 6.71 \pm 0.13 \quad 4.28 \pm 0.10 \quad 1.28 \pm 0.03^{\mathrm{c}} \quad 1.14 \pm 0.05$

${ }^{\mathrm{a}} p<0.05 ;{ }^{\mathrm{b}} p<0.01$ between diabetic subjects with and without AU (ANCOVA, controlling for age, sex, body mass index and $\left.\mathrm{HbA}_{1}\right) ;{ }^{\mathrm{c}} p<0.01 ;{ }^{\mathrm{d}} p<0.001$ between control subjects and diabetic subjects without AU (ANCOVA controlling for age, sex and body mass index). AU + either at the baseline $(n=21)$ or at the 5 -year examination $(n=22)$. Twelve diabetic subjects showed persistent microalbuminuria 

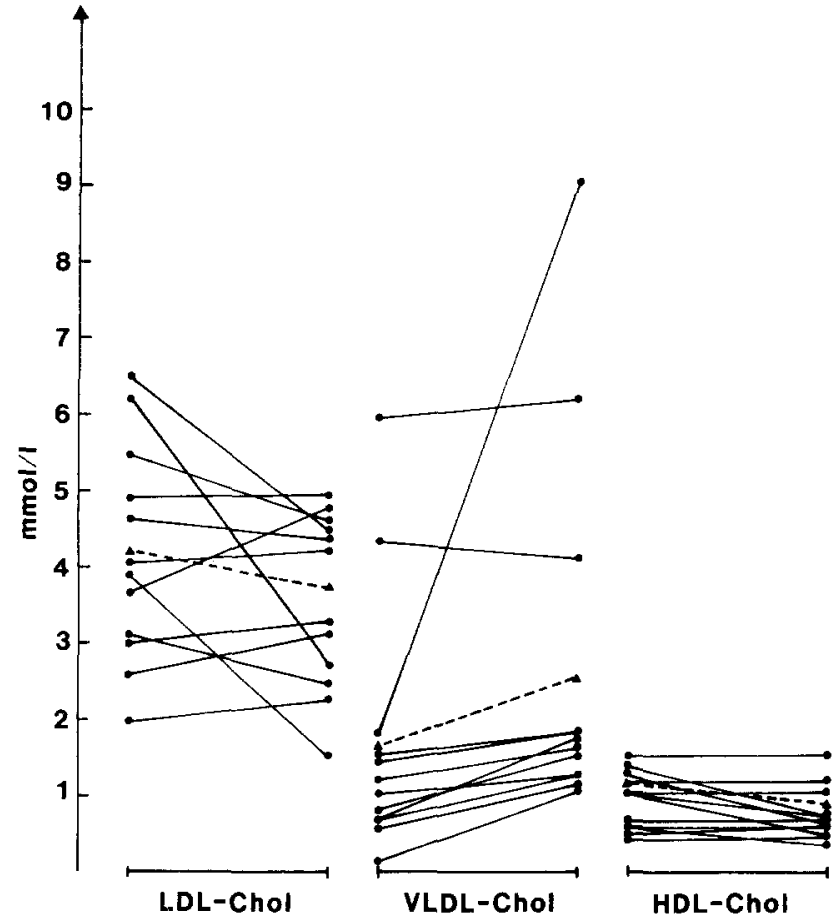

Fig. 2. Serum LDL-, HDL- and VLDL-cholesterol (-chol) and serum VLDL- and LDL-triglycerides ( $\mathrm{Tg}$ ) in diabetic subjects $(n=12)$ with microalbuminuria ( $>35 \mathrm{mg} / 24 \mathrm{~h}$ ) both at the baseline and at the 5-year examination. ( $\wedge$ the mean values of each examination). The changes from the baseline to the 5-year examination were significant for VLDL- and HDL-cholesterol and VLDL- and LDL-triglyceride levels $(p<0.05$, paired $t$-test)

to the presence of microalbuminuria, and in control subjects both at the baseline and at the 5-year examination. There were no differences in these values between diabetic subjects with and without microalbuminuria at the baseline examination, but at the 5-year follow-up HDL-cholesterol was significantly lower and VLDL-cholesterol higher in diabetic patients with microalbuminuria than in those without after adjustment for age, sex, body mass index and $\mathrm{HbA}_{1}(p<0.05)$.

Diabetic subjects without microalbuminuria had both at the baseline and at the 5-year examination lower HDLcholesterol and higher VLDL-cholesterol, but lower total- and LDL-cholesterol levels compared to nondiabetic control subjects.

Table 3 shows the serum total triglycerides and lipoprotein triglyceride levels at the baseline and at the 5-year examination in diabetic patients according to the microalbuminuria at the baseline and in control subjects. At the baseline examination, there were no differences between diabetic subjects with and without microalbuminuria in serum total triglycerides or lipoprotein triglyceride levels. However, at the 5-year examination total triglycerides and VLDL- and LDL-triglycerides were significantly higher $(p<0.05)$ in diabetic patients with microalbuminuria than in those without.
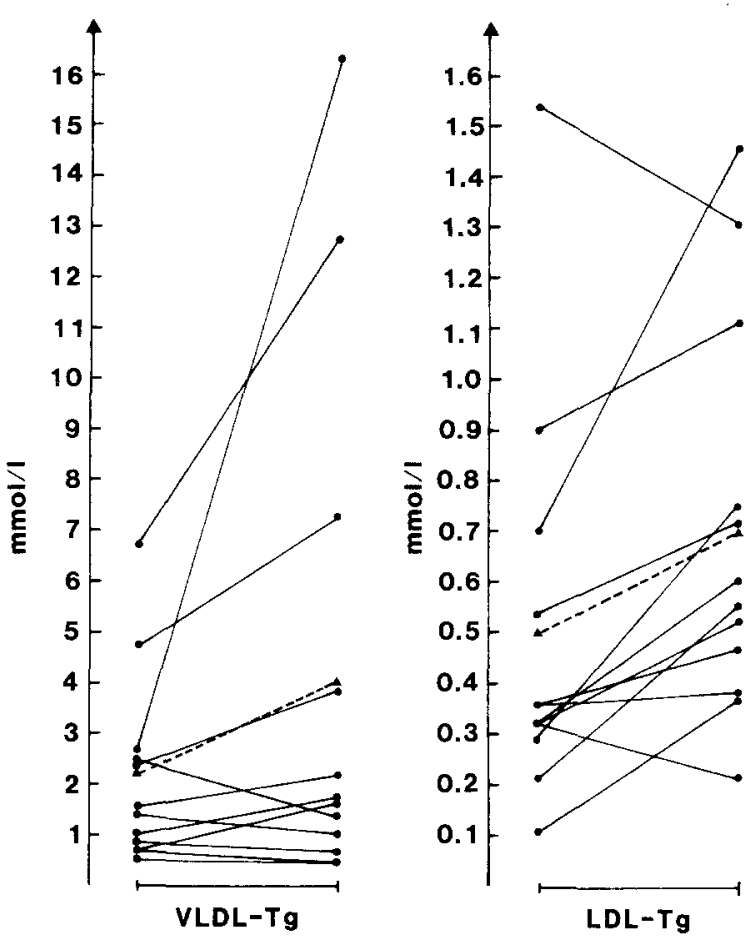

Diabetic subjects without microalbuminuria had higher total- and VLDL-triglycerides both at the baseline and at the 5-year examination compared to non-diabetic control subjects, but no consistent differences were seen between these two groups in LDL- and HDL-triglyceride levels.

At the 5-year examination, $\mathrm{HDL}_{2}$-cholesterol was lower (Table 4) in diabetic subjects with microalbuminuria than in those without, but $\mathrm{HDL}_{3}$-cholesterol was about the same in both diabetic groups. There were no significant differences between Apo- $\mathrm{A}_{1}$ and Apo-Blevels in this regard, although both apoproteins measured tended to be lower in diabetic subjects with microalbuminuria.

Table 3. Serum total triglycerides (Tg; mmol/l) levels and lipoprotein triglyceride levels in diabetic subjects in relation to microalbuminuria (AU), and in control subjects at the baseline and at the 5-year examination

Tg VLDL-Tg LDL-Tg HDL-Tg

\section{Baseline}

AU - $\quad(n=92) \quad 2.39 \pm 0.16 \quad 1.74 \pm 0.14 \quad 0.48 \pm 0.02 \quad 0.18 \pm 0.01$

$\mathrm{AU}+\quad(n=21) \quad 2.45 \pm 0.34 \quad 1.80 \pm 0.28 \quad 0.45 \pm 0.06 \quad 0.21 \pm 0.02$

Control $(n=133) \quad 1.44 \pm 0.07^{\mathrm{d}} 0.94 \pm 0.06^{\mathrm{c}} \quad 0.36 \pm 0.02^{\mathrm{c}} \quad 0.15 \pm 0.01$

5-year

$\mathrm{AU}-\quad(n=91 \quad 2.38 \pm 0.16 \quad 1.80 \pm 0.16 \quad 0.46 \pm 0.02 \quad 0.13 \pm 0.01$ $\mathrm{AU}+\quad(n=22) \quad 4.24 \pm 0.90^{\mathrm{a}} 3.47 \pm 0.84^{\mathrm{a}} 0.62 \pm 0.07^{\mathrm{b}} 0.16 \pm 0.02$ Control $(n=126) \quad 1.55 \pm 0.08^{\mathrm{d}} 1.03 \pm 0.07^{\mathrm{d}} \quad 0.40 \pm 0.02 \quad 0.19 \pm 0.01$

${ }^{\mathrm{a} p<0.05,{ }^{\mathrm{b}} p<0.01 \text { between diabetic subjects with and without }}$ AU (ANCOVA, controlling for age, sex, body mass index and $\left.\mathrm{HbA}_{1}\right) ;{ }^{c} p<0.05,{ }^{\mathrm{d}} p<0.01$ between control subjects and diabetic subjects without AU (ANCOVA controlling for age, sex and body mass index). AU + either at the baseline $(n=21)$ or at the 5 -year examination $(n=22)$. Twelve diabetic subjects showed persistent microalbuminuria 


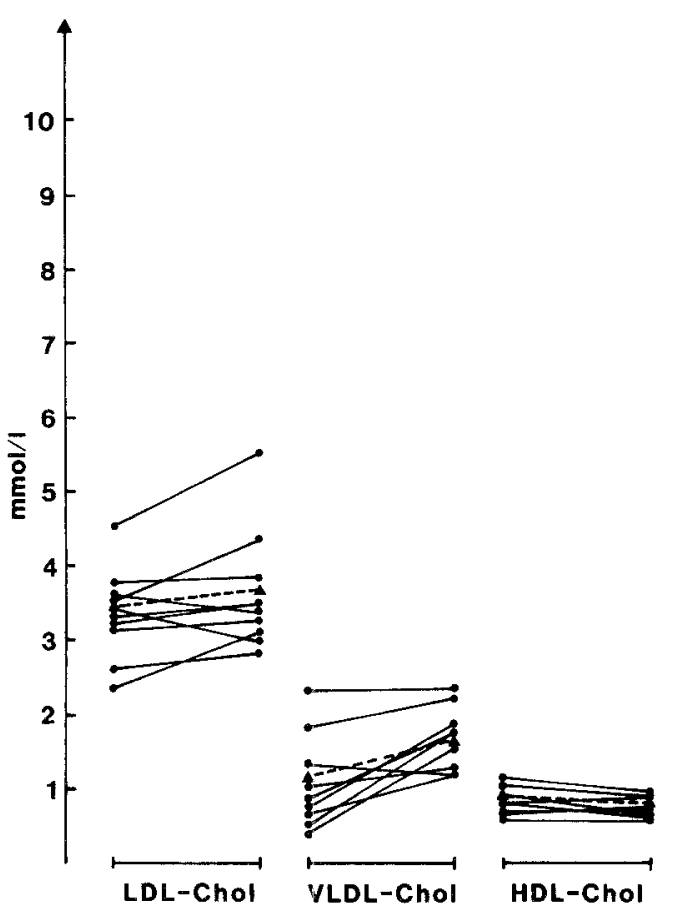

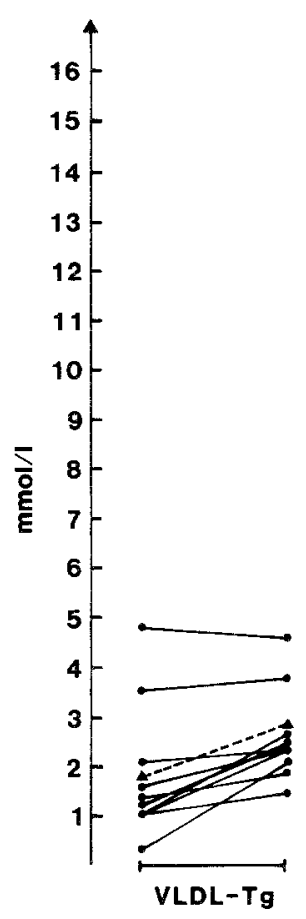

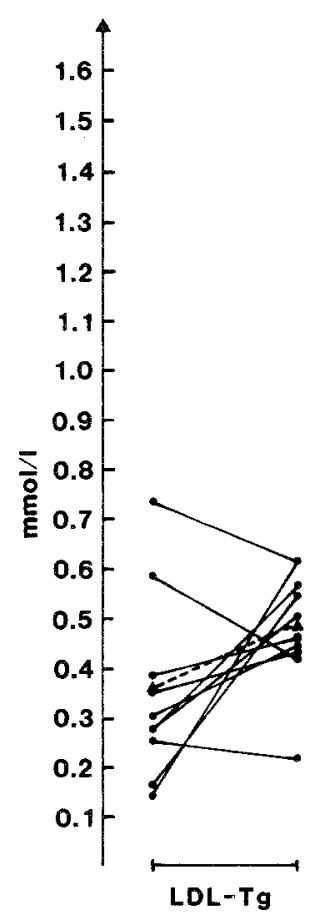

Fig. 3. Serum LDL-, HDLand VLDL-cholesterol (-chol) and serum VLDLand LDL-triglycerides $(\mathrm{Tg})$ in diabetic subjects $(n=10)$ with microalbuminuria ( $\triangleq 35 \mathrm{mg}$ / $24 \mathrm{~h})$ at the 5-year examina-

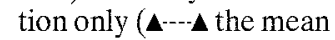
values of each examination). The changes from the baseline to the 5-year examination were significant for VLDL- cholesterol and VLDL- triglycerides $(p<0.05$, paired $t$-test $)$
Diabetic patients without microalbuminuria had lower $\mathrm{HDL}_{2}$-cholesterol and $\mathrm{ApoA}_{1}$ levels at the 5-year examination compared to non-diabetic control subjects. The difference in $\mathrm{ApoA}_{1}$ levels was not, however, statistically significant after adjustment for age, body mass index and sex. The $\mathrm{HDL}_{3^{-}}$and Apo-B levels were identical in these groups.

Figures 2 and 3 show the LDL-, VLDL- and HDLcholesterol and VLDL- and LDL-triglyceride levels in diabetic patients with persistent microalbuminuria $(n=12)$ and in patients with microalbuminuria at the 5year examination only $(n=10)$. The VLDL-cholesterol, VLDL-triglycerides and LDL-triglycerides showed an increase and HDL-cholesterol a decrease during the 5year follow-up both in diabetic subjects with persistent and new microalbuminuria, but no significant change in LDL-cholesterol level was observed in either group. The only significant change in those nine diabetic patients in whom microalbuminuria disappeared was the decrease in HDL-cholesterol levels $(1.32 \pm 0.13 \mathrm{mmol} / \mathrm{l}$ at the baseline vs $1.07 \pm 0.12 \mathrm{mmol} / \mathrm{l}$ at the 5-year examination; $p<0.05$ ).

Table 4. Serum $\mathrm{HDL}_{2}$ and $\mathrm{HDL}_{3}$-cholesterol $\left(\mathrm{HDL}_{2}-\mathrm{C}, \mathrm{HDL}_{3}-\mathrm{C}\right.$; $\mathrm{mmol} / \mathrm{l})$ and apolipoproteins $\mathrm{A}_{1}$ and $\mathrm{B}$ (Apo- $\left.\mathrm{A}_{1}, \mathrm{Apo}-\mathrm{B} ; \mathrm{g} / \mathrm{l}\right)$ in diabetic subjects in relation to microalbuminuria ( $A U)$, and in control subjects at the 5-year examination

\begin{tabular}{llllll}
\hline & & $\mathrm{HDL}_{2}-\mathrm{C}$ & $\mathrm{HDL}_{3}-\mathrm{C}$ & $\mathrm{Apo}-\mathrm{A}_{1}$ & Apo-B \\
\hline $\mathrm{AU}-$ & $(n=91)$ & $0.77 \pm 0.03$ & $0.30 \pm 0.01$ & $1.58 \pm 0.03$ & $1.62 \pm 0.05$ \\
$\mathrm{AU}+$ & $(n=22)$ & $0.62 \pm 0.05^{\mathrm{a}}$ & $0.31 \pm 0.02$ & $1.47 \pm 0.06$ & $1.52 \pm 0.07$ \\
Control & $(n=126)$ & $0.98 \pm 0.03^{\mathrm{b}}$ & $0.30 \pm 0.07$ & $1.72 \pm 0.03$ & $1.62 \pm 0.05$ \\
\hline
\end{tabular}

a $p<0.05$ between diabetic subjects with and without AU (ANCO$\mathrm{VA}$, controlling for age, sex, body mass index and $\left.\mathrm{HbA}_{1}\right) ;{ }^{\mathrm{b}} p<0.05$ between control subjects and diabetic subjects without AU (ANCOVA controlling for age, sex and body mass index)

\section{Discussion}

In the present study we examined the association of slightly increased albumin excretion (microalbuminuria) to serum lipid and lipoprotein levels both at the time of diagnosis and after five years in a representative group of newly diagnosed Type 2 diabetic patients. The definition of increased urinary albumin excretion was based on the highest value found in non-diabetic control subjects at the baseline study ( $<35 \mathrm{mg} / 24 \mathrm{~h}$ ). Urinary tract infection as a cause of albuminuria was excluded. Diabetic patients with albuminuria did not show hypertension or congestive heart failure more frequently than those without albuminuria. The diabetic patients with albuminuria had somewhat higher serum creatinine and lower creatinine clearance, but the renal function was within the normal range by these parameters. In all patients urinary albumin was below the level of clinically manifest proteinuria $(<0.5 \mathrm{~g} / 24 \mathrm{~h})$ i. e. they had microalbuminuria. The prevalence of microalbuminuria in diabetic subjects remained about the same (19-20\%) at both examinations. The increased urinary albumin excretion seems to be an early finding in the clinical course of Type 2 diabetes [24] and may be partly functional and thus, reversible as in Type 1 diabetes [25]. In the present study, about a half of the diabetic subjects showed persistent microalbuminuria.

At the baseline study, no obvious differences were found in serum lipids and lipoproteins in diabetic patients with microalbuminuria compared to diabetic patients without. However, at the 5-year examination an elevated VLDL-cholesterol and decreased HDL-cholesterol levels in diabetic patients with microalbuminuria was seen. Similarly, the diabetic subjects with microalbuminuria had higher VLDL- and LDL-triglycerides than those diabetic patients without microalbuminuria. Only one study on 
serum lipid changes in Type 2 diabetes with albuminuria has been published so far [17]. This cross-sectional study showed, in accordance with our study, that diabetic patients with albuminuria had lower HDL-cholesterol and higher triglyceride levels compared to diabetic patients without albuminuria. Only total cholesterol, HDL-cholesterol and total triglycerides were measured in this previous study. Cross-sectional studies concerning serum lipid and lipoprotein abnormalities in Type 1 diabetic patients with clinical or subclinical albuminuria have shown that patients with increased urinary albumin excretion have in general higher total cholesterol and LDL- and VLDL-cholesterol levels, and also higher triglyceride and Apo-B levels but lower HDL-cholesterol and Apo-A levels than patients with undetectable urinary albumin [10-15]. Although the lipoprotein patterns of the major types of diabetes are quite different [26], albuminuria in both types of diabetes is associated with compositional changes in lipids and lipoproteins favouring atherogenesis [16]. Furthermore, according to our findings microalbuminuria appears to predict the development of these lipid and lipoprotein abnormalities, and they develop before any renal damage or urine abnormalities can be discovered by conventional methods.

An increase in serum and VLDL-triglycerides and a decrease in HDL-cholesterol is a typical lipid abnormality in Type 2 diabetes [26] and is found already at the time of diagnosis, as was the case in our patients [23]. Furthermore, VLDL-cholesterol and LDL-triglycerides were elevated in diabetic subjects compared to non-diabetic subjects in our study. In Type 2 diabetes, the VLDL-triglyceride production is increased and its catabolism to LDL is impaired thus leading to accumulation of atherogenic VLDL remnants [26]. High VLDL-cholesterol and LDL-triglyceride levels are indicators for the elevation of the plasma concentration of these VLDL remnants [27]. A low HDL-cholesterol level is also characteristic of Type 2 diabetes and is associated with an excess of vascular disease [8]. According to our results, the presence of microalbuminuria aggravates these lipid and lipoprotein compositional abnormalities. The mechanism underlying this phenomenon is not known. In the nephrotic syndrome lipoprotein synthesis is increased as a response to albumin loss [28], but the effect of microalbuminuria on lipids and lipoproteins is largely unknown. It has been speculated that microalbuminuria would be associated with transglomerular loss of smaller $\mathrm{HDL}_{3}$-subspecies resulting in a reduced conversion to $\mathrm{HDL}_{2}$ and thus in a net decrease in the serum total HDLcholesterol. An increased urinary loss of Apo- $\mathrm{A}_{1}$ may lead to an inactivation of lecithin cholesterol acyl transferase which may contribute to low HDL-cholesterol levels [14]. Glycosylation of plasma lipoprotein lipase leading to an inhibition of this enzyme and to an increase in VLDL-cholesterol and a decrease in HDL-cholesterol has also been suggested as a possible underlying mechanism for lipid abnormalities in diabetic patients with albuminuria [13]. In the present study diabetic subjects with persistent albuminuria showed somewhat elevated fasting plasma insulin levels suggestive of insulin resistance, but the relationship of insulin resistance to microalbuminuria has not been elucidated in detail.
Diabetic patients with microalbuminuria were more hyperglycaemic than others indicating that metabolic control may contribute to the appearance of proteinuria, but hyperglycaemia did not explain the observed differences in serum and lipoprotein lipids and Apo- $\mathrm{A}_{1}$ and Apo-B between the diabetic groups with or without microalbuminuria at the 5-year examination. It has been shown in other studies that subclinical proteinuria is reversible with improved metabolic control by low calorie diet in Type 2 diabetic patients [29-30].

The association of albuminuria to elevated blood pressure in patients with Type 1 diabetes is well-known but the information from patients with Type 2 diabetes is contradictory. A positive correlation has been found between diastolic blood pressure and albuminuria in diabetic men but not in diabetic women [17], while another study showed a positive correlation between albuminuria and systolic blood pressure [5]. In one study, hypertensive diabetic subjects have shown a higher frequency of albuminuria than normotensive subjects [24] whereas others have failed to establish any association between blood pressure and proteinuria in Type 2 diabetic patients [31]. Different results may be due to the differences in patient selection and the high frequency of hypertension in patients with Type 2 diabetes, treatment of hypertension being one of the confounding factors. In general, hypertension was well-controlled in our diabetic patients judging from the frequent use of antihypertensive agents and the mean blood pressure levels.

Our results indicate that in patients with Type 2 diabetes microalbuminuria predicts the further decrease in HDL-cholesterol and elevation in LDL- and VLDLtriglyceride and VLDL-cholesterol levels. The present data also suggest that increased cardiovascular morbidity and mortality in Type 2 diabetic patients with albuminuria may be explained, in part, by the more atherogenetic lipoprotein profile. In this respect it was interesting that we found these lipoprotein compositional abnormalities (low HDL-cholesterol, high VLDL-cholesterol and high VLDL- and LDL-triglycerides) to be predictive of future peripheral vascular disease [34]. Because both subclinical albuminuria and lipid and lipoprotein abnormalities [26] may be reversible with improved metabolic control and weight loss in patients with Type 2 diabetes, a more stringent approach of treating hyperglycaemia and obesity is needed in Type 2 diabetic patients, in order to reduce excess cardiovascular morbidity and mortality.

Acknowledgements. This study was financially supported by grants from Yrjö Jahnsson Foundation, the Finnish Foundation of Diabetes Research, Nordisk Insulinfond, Denmark, North Savo Regional Fund of the Finnish Cultural Foundation, Orion Corporation Research Foundation, and Helena Vuorenmies Foundation. The skillful secretarial assistance of Ms. E-M. Oittinen in the preparation. of the manuscript is gratefully acknowledged.

\section{References}

1. Viberti GC, Hill RD, Jarrett RJ, Argyropoulos A, Mahmud U, Keen H (1982) Microalbuminuria as a predictor of clinical nephropathy in insulin-dependent diabetes mellitus. Lancet I: 1430-1432 
2. Mogensen CE (1984) Microalbuminuria predicts clinical proteinuria and early mortality in maturity-onset diabetes. NEngl J Med 310:356-360

3. Borch-Johnsen K, Andersen PK, Deckert T (1985) The effect of proteinuria on relative mortality in Type 1 (insulin-dependent) diabetes mellitus. Diabetologia 28: 590-596

4. Jarrett RJ, Viberti GC, Argyropoulos A, Hill DR, Mahmud U, Murrells TJ (1984) Microalbuminuria predicts mortality in noninsulin-dependent diabetes. Diabetic Med 1:17-19

5. Schmitz A, Vaeth M (1988) Microalbuminuria: a major risk factor in non-insulin-dependent diabetes. A 10-year follow-up study of 503 diabetic patients. Diabetic Med 5: 126-134

6. Nelson RG, Pettitt DJ, Carraher MJ, Baird HR, Knowler WC (1988) Effect of proteinuria on mortality in NIDDM. Diabetes 37: 1499-1504

7. Yudkin JS, Forrest RD, Jackson CA (1988) Microalbuminuria as predictor of vascular disease in non-diabetic subjects. Islington diabetes survey. Lancet II: $530-533$

8. Pyörälä K, Laakso M, Uusitupa M (1987) Diabetes and atherosclerosis: an epidemiologic view. Diab Metab Rev 3: 463-524

9. Mathiesen ER, Oxenbøll B, Johansen K, Svendsen PA, Deckert $\mathrm{T}$ (1984) Incipient nephropathy in Type 1 (insulin-dependent) diabetes. Diabetologia 26: 406-410

10. Eckel RH, McLean E, Albers JJ, Cheung MC, Bierman EL (1981) Plasma lipids and microangiopathy in insulin-dependent diabetes mellitus. Diabetes Care 4: 447-453

11. Vannini P, Giavarella A, Flammini M, Bargossi AM, Forlani G, Borgnino LC, Orsoni G (1984) Lipid abnormalities in insulin-dependent diabetic patients with albuminuria. Diabetes Care 7 : $151-154$

12. Winocour PH, Durrington PN, Ishola M, Anderson DC, Cohen $H$ (1987) Influence of proteinuria on vascular disease, blood pressure, and lipoproteins in insulin dependent diabetes mellitus. Br Med J 294: 1648-1651

13. Jensen T, Stender S, Deckert T (1988) Abnormalities in plasma concentrations of lipoproteins and fibrinogen in Type 1 (insulindependent) diabetic patients with increased urinary albumin excretion. Diabetologia 31: 142-145

14. Watts GF, Naumova R, Slavin BM, Morris RW, Houlston R, Kubal C, Shaw KM (1989) Serum lipids and lipoproteins in insulin-dependent diabetic patients with microalbuminuria. Diabetic Med 6: 25-30

15. Jones SL, Close CF, Mattock MB, Jarrett RJ, Keen H, Viberti GC (1989) Plasma lipid and coagulation factor concentrations in insulin dependent diabetics with microalbuminuria. Br Med J 298: $487-490$

16. Keen H (1987) Macrovascular disease in diabetes mellitus. In: Andreani D, Crepaldi G, Di Mario U, Pozza G (eds) Diabetic complications: early diagnosis and treatment, Vol 1. Wiley, Chichester New York Brisbane Toronto Singapore, pp 3-12

17. Mattock MB, Keen H, Viberti GC, El-Gohari MR, Murrells TJ, Scott GS, Wing JR, Jackson PG (1988) Coronary heart disease and urinary albumin excretion rate in Type 2 (non-insulin-dependent) diabetic patients. Diabetologia 31: $82-87$

18. Uusitupa M, Siitonen O, Aro A, Pyörälä K (1985) Prevalence of coronary heart disease, left ventricular failure and hypertension in middle-aged, newly diagnosed Type 2 (non-insulin-dependent) diabetic subjects. Diabetologia 28: 22-27
19. WHO Expert Committee (1980) Second report on diabetes mellitus. Geneva, World Health Organization. (Technical Report Series 646)

20. Korhonen T, Uusitupa M, Aro A, Kumpulainen T, Siitonen O, Voutilainen E, Pyörälä K (1987) Efficacy of dietary instructions in newly diagnosed non-insulin-dependent diabetic patients. Comparison of two different patient education regimens. Acta Med Scand 222: 323-331

21. Uusitupa M, Siitonen O, Penttilä I, Aro A, Pyörälä K (1987) Proteinuria in newly diagnosed type II diabetic patients. Diabetes Care 10: 191-194

22. Penttilä IM, Voutilainen E, Laitinen P, Juutilainen P (1981) Comparison of three different analytical and precipitation methods for the direct estimation of serum high-density lipoprotein cholesterol. Scand J Chem Lab Invest 41:353-360

23. Uusitupa M, Siitonen O, Voutilainen E, Aro A, Hersio K, Pyörälä K, Penttilä I, Ehnholm C (1986) Serum lipids and lipoproteins in newly diagnosed non-insulin-dependent (type 2) diabetic patients, with special reference to factors influencing HDL-cholesterol and triglyceride levels. Diabetes Care 9: 17-22

24. Fabre J, Balant LP, Dayer PG, Fox HM, Verner AT (1982) The kidney in maturity-onset diabetes mellitus: a clinical study of 510 patients. Kidney Int 21: 730-738

25. Mogensen CE, Christensen CK, Vittinghus E (1983) The stages in diabetic renal disease with emphasis on the stage of incipient diabetic nephropathy. Diabetes 32 (Suppl 2): 64.78

26. Kostner GM, Karadi I (1988) Lipoprotein alterations in diabetes mellitus. Diabetologia 31: 717-722

27. Betteridge DJ (1989) Diabetes, lipoprotein metabolism and atherosclerosis. Br Med Bull 45: 285-311

28. Chan MK, Persaud JW, Ramdial L, Varghese Z, Sweny P, Moorhead JF (1981) Hyperlipidaemia in untreated nephrotic syndrome, increased production or decreased removal? Clin Chim Acta 117: 317-323

29. Mohamed A, Wilkin T, Leatherdale BA, Rawe D (1984) Response of urinary albumin to submaximal exercise in newly diagnosed non-insulin-dependent diabetes. Br Med J 1: 1342-1343

30. Vasquez B, Flock EV, Savage PJ, Nagulesparan M, Bennion LJ, Baird HR, Bennett PH (1984) Sustained reduction of proteinuria in Type 2 (non-insulin-dependent) diabetes following dietinduced reduction of hyperglycaemia. Diabetologia 26: 127-133

31. Jerums G, Cooper ME, Seeman E, Murray RML, McNeil JJ (1987) Spectrum of proteinuria in type I and type II diabetes. Diabetes Care 10:419-427

32. Uusitupa M, Niskanen L, Siitonen O, Voutilainen E, Pyörälä K (1990) 5-year incidence of atherosclerotic vascular diseases in relation to general risk factors, insulin level and lipoprotein abnormalities in non-insulin-dependent diabetic and non-diabetic subjects. Circulation (in press)

Received: 11 July 1989

and in revised form: 13 November 1989

Dr. L. Niskanen

Department of Medicine

Kuopio University Central Hospital

SF-70210 Kuopio

Finland 